Article

\title{
Genotype-Phenotype Correlation in Hypertrophic Cardiomyopathy: New Variant p.Arg652Lys in MYH7
}

\author{
Guido Antoniutti ${ }^{1}$ (D), Fiama Giuliana Caimi-Martinez ${ }^{1}$ (D), Jorge Álvarez-Rubio ${ }^{1,2}{ }^{\text {, Paula Morlanes-Gracia }}{ }^{3}$, \\ Jaume Pons-Llinares 2,4, Blanca Rodríguez-Picón ${ }^{5}$, Elena Fortuny-Frau 2,4 , Laura Torres-Juan 2,6 (D), \\ Damian Heine-Suner ${ }^{2,6}$ (D) and Tomas Ripoll-Vera $1,2,7, * \mathbb{D}$
}

Citation: Antoniutti, G.;

Caimi-Martinez, F.G.; Álvarez-Rubio,

J.; Morlanes-Gracia, P.; Pons-Llinares,

J.; Rodríguez-Picón, B.; Fortuny-Frau,

E.; Torres-Juan, L.; Heine-Suner, D.;

Ripoll-Vera, T. Genotype-Phenotype

Correlation in Hypertrophic

Cardiomyopathy: New Variant

p.Arg652Lys in MYH7. Genes 2022,

13, 320. https://doi.org/

10.3390 /genes 13020320

Academic Editor: Paolo Cinelli

Received: 10 December 2021

Accepted: 7 February 2022

Published: 9 February 2022

Publisher's Note: MDPI stays neutral with regard to jurisdictional claims in published maps and institutional affiliations.

Copyright: (C) 2022 by the authors. Licensee MDPI, Basel, Switzerland. This article is an open access article distributed under the terms and conditions of the Creative Commons Attribution (CC BY) license (https:// creativecommons.org/licenses/by/ $4.0 /)$
1 Cardiology Department, Hospital Universitario Son Llàtzer, 07198 Palma de Mallorca, Spain; guidoantoniutti@hotmail.com (G.A.); fiamacaimi91@gmail.com (F.G.C.-M.); jalvarezr@hsll.es (J.Á.-R.)

2 Health Research Institute of the Balearic Islands (IdISBa), 07120 Palma de Mallorca, Spain; jaumea.pons@ssib.es (J.P.-L.); elena.fortuny@ssib.es (E.F.-F.); laura.torresjuan@ssib.es (L.T.-J.); damian.heine@ssib.es (D.H.-S.)

3 Cardiology Department, Hospital Clínico Universitario Lozano Blesa, 50009 Zaragoza, Spain; pmorlanesg@gmail.com

4 Cardiology Department, Hospital Universitario Son Espases, 07120 Palma de Mallorca, Spain

5 Cardiology Unit, Hospital Mateu Orfila, 07703 Menorca, Spain; shirljovi@gmail.com

6 Unit of Molecular Diagnostics and Clinical Genetics, Hospital Universitario Son Espases, 07120 Palma de Mallorca, Spain

7 CIBEROBN (Physiopathology of Obesity and Nutrition), 28029 Madrid, Spain

* Correspondence: tripoll@hsll.es

Abstract: Hypertrophic cardiomyopathy (HCM) is a genetic disease characterised by increased left ventricle (LV) wall thickness caused by mutations in sarcomeric genes. Finding a causal mutation can help to better assess the proband's risk, as it allows the presence of the mutation to be evaluated in relatives and the follow-up to be focused on carriers. We performed an observational study of patients with HCM due to the novel p.Arg652Lys variant in the MYH7 gene. Eight families and 59 patients are described in the follow-up for a median of 63 months, among whom $39(66 \%)$ carry the variant. Twenty-five (64\%) of carriers developed HCM. A median maximum LV wall thickness of $16.5 \mathrm{~mm}$ was described. The LV hypertrophy was asymmetric septal in $75 \%$ of cases, with LV outflow tract obstruction in $28 \%$. The incidence of a composite of serious adverse cardiovascular events (sudden death, aborted sudden death, appropriate implantable cardiac defibrillator discharge, an embolic event, or admission for heart failure) was observed in five $(20 \%)$ patients. Given the finding of the p.Arg652Lys variant in patients with HCM, but not in controls, with evident segregation in patients with HCM from eight families and the location in an active site of the protein, we can define this variant as likely pathogenic and associated with the development of HCM.

Keywords: hypertrophic cardiomyopathy; cardiomyopathies; cardiomyopathy; genetic; genetic testing; next-generation sequencing; NGS for diagnostics of CVDs; variant interpretation; variant classification

\section{Introduction}

Hypertrophic Cardiomyopathy (HCM) is a genetic disease characterised by increased left ventricle (LV) wall thickness caused by variants in sarcomeric genes [1]. To date, more than 1500 variants associated with the disease have been described, usually with an autosomal dominant pattern of inheritance. Each child of a patient with the variant has a $50 \%$ chance of inheriting it, although penetrance is incomplete and the age of presentation in those who develop the disease is variable [2]. The most frequently affected genes are MYH7 and MYBPC3, which encode the $\beta$-myosin heavy chain ( $\beta$-MHC) and the myosin binding protein $\mathrm{C}$, respectively. Together, variants in $M Y H 7$ and MYBPC3 are identified in $70 \%$ of patients with HCM and a positive result in the genetic analysis [3]. 
Although the hereditary nature of the disease has been known since 1961 [4], MYH7 was the first gene described to cause HCM in 1990 [5,6]; since then, multiple variants capable of producing the disease have been discovered $[7,8]$.

Finding a causal variant of the disease in patients with HCM can sometimes help to better assess the proband's risk; however, above all, it allows the presence of the variant to be evaluated in relatives and the follow-up to be focused on carriers [9]. The profitability of the genetic study in patients affected by HCM is around 50\%, despite the new technologies that are available [10]. Describing new pathogenic or likely pathogenic variants increases diagnostic performance, allows better risk characterization, reduces the number of patients in follow-up after ruling out their presence, and reduces health costs [11].

We have observed the presence of a new variant at position 1955 of $M Y H 7$, which causes the substitution of the amino acid arginine at position 652 with lysine (NP_000248.2: p.Arg652Lys, NM_000257.2:c.1955G>A) in $\beta-M H C$ in a series of patients diagnosed with HCM belonging to non-related families in a community in Spain. This finding suggests that the p.Arg652Lys variant could be associated with the development of the disease.

\section{Objective}

To determine the genotype-phenotype association of the new variant p.Arg652Lys in $M Y H 7$ in patients with HCM.

\section{Materials and Methods}

A retrospective and observational study in which patients with a diagnosis of HCM and a finding of the p.Arg652Lys variant in MYH7 were analysed. From those patients, family screening was carried out, drawing up a genealogical tree of at least three generations and studying the first-degree relatives of the affected individuals both clinically and genetically.

\subsection{Patient Selection}

Patients that followed-up in the cardiology services of the Balearic Islands (Spain) with a diagnosis of HCM were analysed using phenotypic and genetic investigations between January 2001 and April 2021. The patients with a finding of the p.Arg652Lys variant were selected.

The family histories of at least three generations of each proband were investigated (Figures S1-S8 in Supplementary Materials), and the phenotype of the first-degree relatives of those who presented the variant are described (Figure 1).

HCM was defined as the presence of a maximum left ventricular wall thickness (LVWT) equal to or greater than $15 \mathrm{~mm}$, determined by cardiac imaging techniques, or equal to or greater than $13 \mathrm{~mm}$ in those with a family history of HCM, according to the criteria expressed in the latest consensus from the European Society of Cardiology in 2014 [12,13] and the American College of Cardiology/American Heart Association in 2020. 


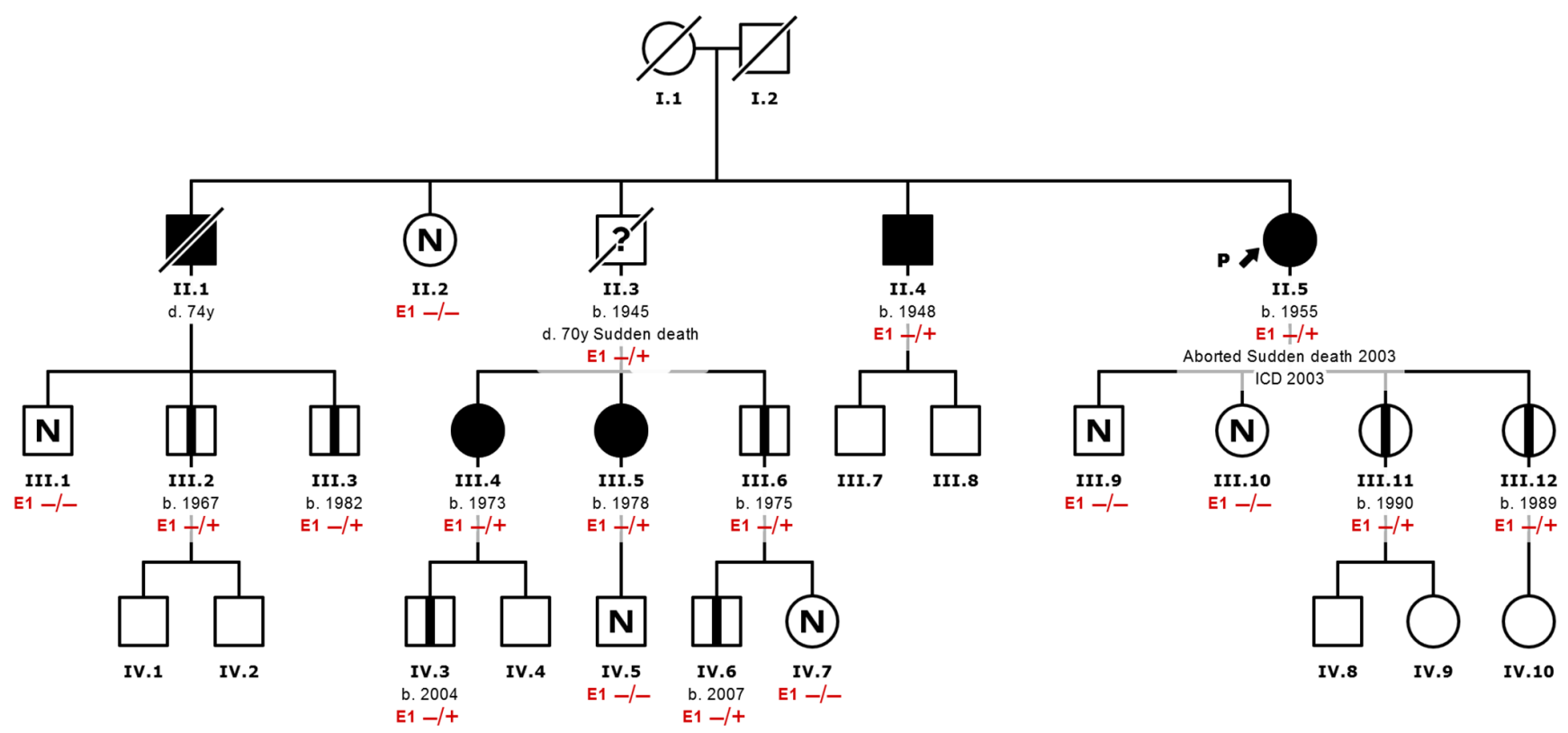

Figure 1. Family tree of a typical family with HCM. (II.5 corresponds to index case $\mathrm{N}^{\circ} 7$ in Table 1) Most HCMs are inherited in an autosomal dominant fashion. Affected individuals are shown in black, and healthy carriers of the p.Arg652Lys variant (E1) are shown with a central black mark. Using a genetic panel, the variant was identified in the proband (arrow) after an episode of aborted sudden death. Other members of the family who inherited the variant were affected clinically but without severe events such as the proband, which shows variable expressivity of the variant. ICD: Implantable Cardiac Defibrillator. - / - : Variant not found. - /+: Heterozygous variant found.

\subsection{Genetic Analysis}

Given the diagnosis of HCM in the index cases, a genetic analysis was carried out to determine the presence of variants associated with the disease. The samples were analysed in three different Spanish laboratories: Health in Code (A Coruña, Spain), Imegen (Valencia, Spain), and Unidad de Diagnóstico Molecular y Genética Clínica del Hospital Universitario Son Espases (Mallorca, Spain), according to availability at the time of evaluation of each patient.

The technique used for index patients was Sanger or Next Generation Sequencing (NGS). A minimum of five genes (Sanger) and a maximum of 287 genes (NGS) were analysed, among which the five main sarcomeric genes were always included ( $M Y H 7$, MYBPC3, TNNT2, TNNI3, and TPM1). 
Table 1. Characteristics of the population with findings of the p.Arg652Lys variant in MYH7.

\begin{tabular}{|c|c|c|c|c|c|c|c|c|c|c|c|c|c|c|c|c|c|c|c|c|}
\hline \multicolumn{15}{|c|}{ Population Characteristics } & \multicolumn{6}{|c|}{ Clinical Behavior } \\
\hline $\begin{array}{l}\text { Family } \\
\text { Num- } \\
\text { ber }\end{array}$ & $\begin{array}{c}\text { Relation } \\
\text { to } \\
\text { Index } \\
\text { Case }\end{array}$ & Sex & $\begin{array}{c}\text { Age at } \\
\text { First } \\
\text { Medical } \\
\text { Contact }\end{array}$ & Phenotype & $\begin{array}{l}\text { Follow- } \\
\text { Up } \\
\text { Time } \\
\text { (Months) }\end{array}$ & $\begin{array}{c}\text { SD FH in } \\
\text { 1st } \\
\text { Degree } \\
\text { Relatives }\end{array}$ & $\begin{array}{l}\text { Clinical Pre- } \\
\text { sentation }\end{array}$ & $\mathrm{AF}$ & NYHA & $\begin{array}{l}\text { MLVWT in } \\
\text { 1st TTE } \\
\text { (mm) }\end{array}$ & $\begin{array}{l}\text { MLVWT in } \\
\text { Follow-Up } \\
\quad(\mathrm{mm})\end{array}$ & $\begin{array}{c}\text { LVOT } \\
\text { Obstruction } \\
>30 \mathrm{mmHg}\end{array}$ & $\begin{array}{c}\text { LVEF at } \\
\text { Diagnosis } \\
(\%)\end{array}$ & $\begin{array}{c}\text { LA } \\
\text { Maximum } \\
\text { Diameter in } \\
\text { Follw-Up } \\
(\mathrm{mm})\end{array}$ & NSVT & $\begin{array}{c}\text { Septal } \\
\text { Reduc- } \\
\text { tion } \\
\text { Ther- } \\
\text { apy }\end{array}$ & $\mathrm{HF}$ & $\begin{array}{l}\text { Embolic } \\
\text { Event } \\
\text { (Age) }\end{array}$ & $\begin{array}{c}\text { SD } \\
\text { (Age) }\end{array}$ & $\begin{array}{l}\text { ASD } \\
\text { (Age) }\end{array}$ \\
\hline \multirow[t]{2}{*}{1} & $\begin{array}{l}\text { Index } \\
\text { case }\end{array}$ & M & 34 & $\mathrm{HCM}$ & 127 & No & Sincope & No & 1 & 22 & 24 & Yes & ? & 35 & & & & & & \\
\hline & Sister & $\mathrm{F}$ & 39 & $\begin{array}{l}\text { Healthy } \\
\text { Carrier }\end{array}$ & 114 & No & $\begin{array}{c}\text { Casual or } \\
\text { family } \\
\text { Screening }\end{array}$ & No & 1 & 11 & 11 & No & 65 & 35 & & & & & & \\
\hline \multirow{3}{*}{2} & Son & M & 51 & HCM & 113 & No & $\begin{array}{c}\text { Casual or } \\
\text { family } \\
\text { Screening }\end{array}$ & No & 1 & 12 & 13 & No & 60 & 35 & & & & & & \\
\hline & Son & M & 45 & HCM & 129 & No & $\begin{array}{c}\text { Casual or } \\
\text { family } \\
\text { Screening }\end{array}$ & No & 1 & 13 & 13 & No & 60 & 35 & & & & & & \\
\hline & Grandson & M & 15 & $\begin{array}{l}\text { Healthy } \\
\text { Carrier }\end{array}$ & 112 & No & $\begin{array}{c}\text { Casual or } \\
\text { family } \\
\text { Screening }\end{array}$ & No & 1 & 9 & 9 & $?$ & ? & $?$ & & & & & & \\
\hline 3 & Mother & $\mathrm{F}$ & 73 & HCM & 15 & No & Angina & No & 1 & 22 & 22 & Yes & 71 & 58 & & & & & & \\
\hline \multirow[t]{3}{*}{4} & $\begin{array}{l}\text { Index } \\
\text { case }\end{array}$ & $\mathrm{F}$ & 53 & HCM & 197 & No & Angina & No & 1 & 11 & 18 & No & ? & 35 & & & Yes & & & \\
\hline & Daughter & $\mathrm{F}$ & 30 & $\begin{array}{l}\text { Healthy } \\
\text { Carrier }\end{array}$ & 63 & No & $\begin{array}{l}\text { Casual or } \\
\text { family } \\
\text { Screening }\end{array}$ & No & 1 & 11 & 11 & No & 60 & 35 & & & & & & \\
\hline & Aunt & $\mathrm{F}$ & 80 & HCM & 114 & No & Palpitations & Yes & 1 & 12 & 12 & No & 71 & 55 & & & & Yes (92) & & \\
\hline \multirow[t]{4}{*}{5} & $\begin{array}{l}\text { Index } \\
\text { case }\end{array}$ & $\mathrm{F}$ & 40 & $\mathrm{HCM}$ & 62 & No & Angina & No & 1 & 20 & 21 & Yes & 60 & 51 & & & & & & \\
\hline & Brother & M & 38 & $\mathrm{HCM}$ & 74 & No & $\begin{array}{l}\text { Casual or } \\
\text { family } \\
\text { Screening }\end{array}$ & No & 1 & 19 & 22 & $\mathrm{Si}$ & 60 & 39 & Yes & & & & & \\
\hline & Daughter & F & 16 & $\begin{array}{l}\text { Healthy } \\
\text { Carrier }\end{array}$ & 85 & No & $\begin{array}{l}\text { Casual or } \\
\text { family } \\
\text { Screening }\end{array}$ & No & 1 & 6 & 9 & No & 60 & 35 & & & & & & \\
\hline & Father & M & 70 & $\mathrm{HCM}$ & 17 & No & $\begin{array}{l}\text { Casual or } \\
\text { family } \\
\text { Screening }\end{array}$ & No & 1 & 14 & 14 & No & 55 & 39 & & & & Yes (69) & & \\
\hline
\end{tabular}


Table 1. Cont.

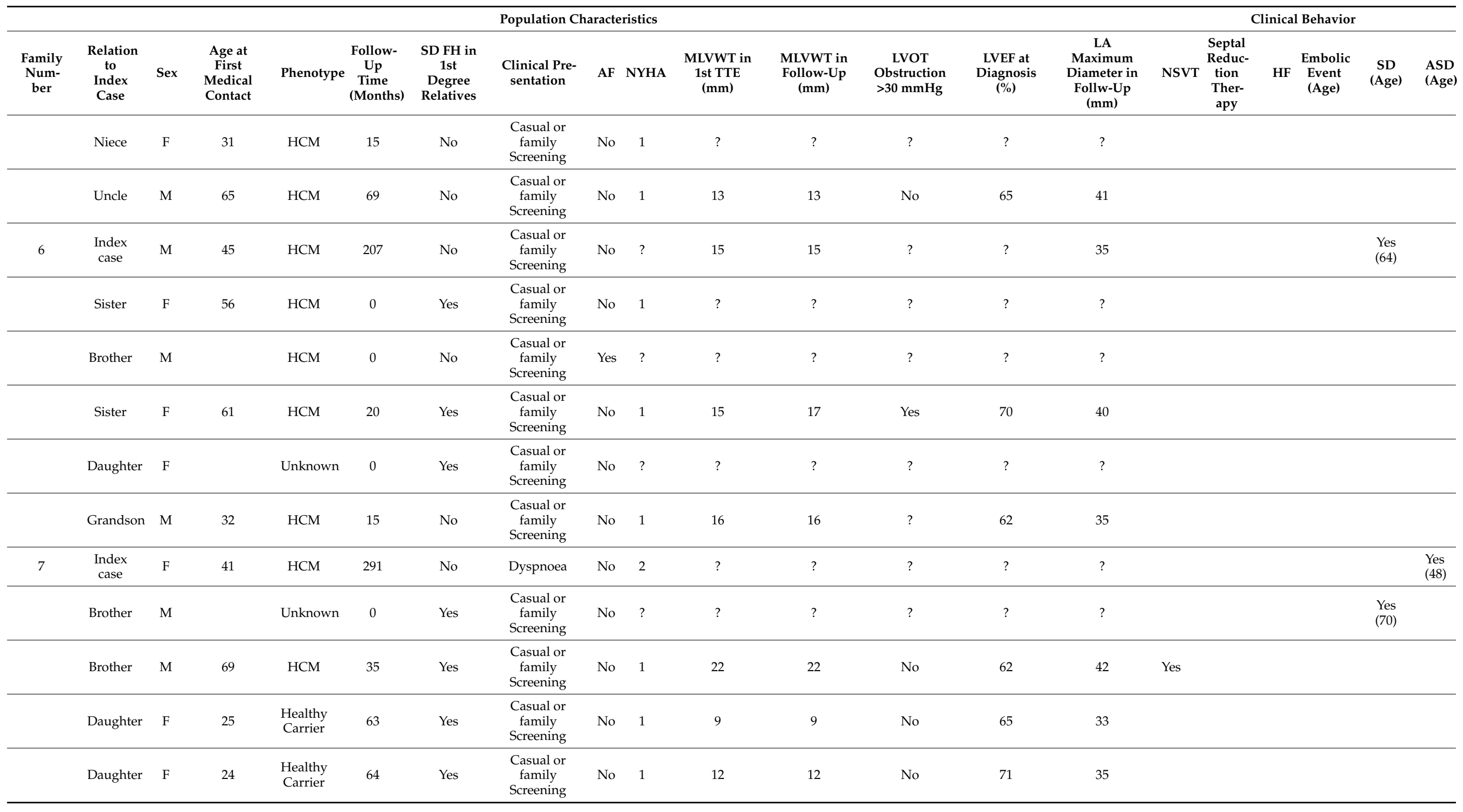


Table 1. Cont.

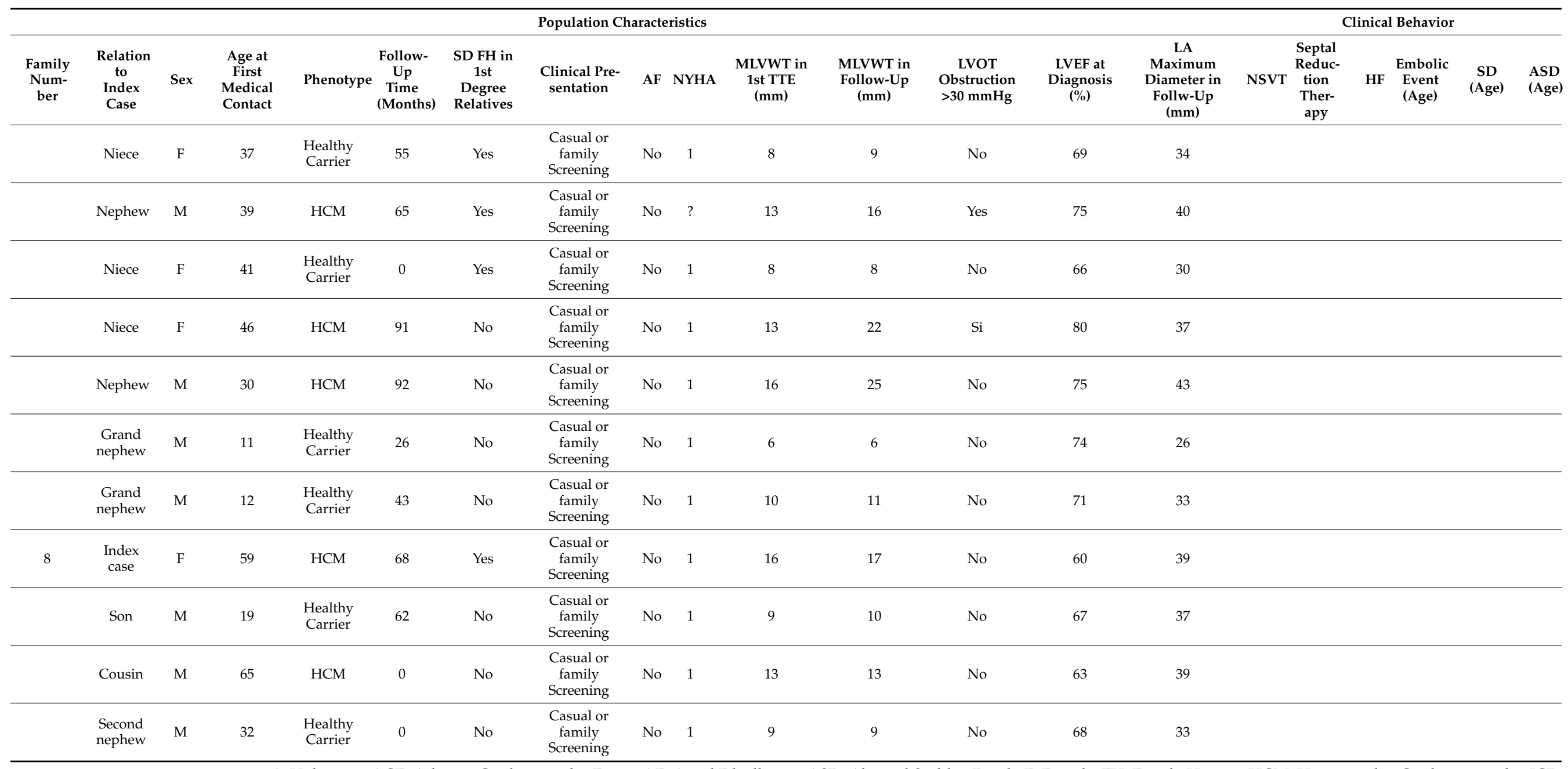

?: Unknown, ACE: Adverse Cardiovascular Event, AF: Atrial Fibrillation, ASD: Aborted Sudden Death, F: Female, FH: Family History, HCM: Hypertrophic Cardiomyopathy, ICD Implantable Cardiac Defibrillator, LA: Left Atrium, LVEF: Left Ventricle Ejection Fraction, LVOT: Left Ventricle Outflow Tract, M: Male, MLVWT: Maximum Left Ventricle Wall Thickness, NSVT: Non-sustained Ventricular Tachycardia, NYHA: New York Heart Association dyspnea classification, PCM: Pacemaker, SD: Sudden Death, SDPP: Sudden Death Primary

Prevention, SDSP: Sudden Death Secondary Prevention, TTE: Transthoracic Echocardiography. 
Variants were filtered using a pre-established protocol based mainly on the probable functional impact on the protein and allelic frequency. Predictive bioinformatics tools were used "in silico". We applied the 2015 consensus guidelines of the American College of Medical Genetics and Genomics and the Association for Molecular Pathology (ACMG/AMP) [14] to classify the variants as pathogenic, likely pathogenic, or variants of uncertain significance. We excluded those considered benign, probably benign, and variants of uncertain significance with a frequency rate $\geq 0.02 \%$ in the GnomAD databases and our private database at Unidad de Diagnóstico Molecular y Genética Clínica del Hospital Universitario Son Espases or in those where co-segregation could not be demonstrated in the cases studied.

The genetic cascade study of the relatives was aimed at evaluating exclusively the variants present in the index case.

\subsection{Clinical Evaluation and Complementary Studies}

Clinical evaluation consisted of the preparation of a detailed medical history, the constitution of a family tree, and a complete physical examination performed by cardiologists belonging to the Family Heart Disease Unit of the Son Llàtzer University Hospital (Palma de Mallorca), Son Espases University Hospital (Palma de Mallorca), and Hospital Mateu Orfila (Mahón, Menorca).

The complementary studies included an electrocardiogram (ECG) and a transthoracic echocardiogram (TTE) both in the index cases and in the family screening study. Cardiac Magnetic Resonance (MRI), 24-h Holter ECG, and stress tests were performed according to the discretion of the treating physician. All investigations were carried out by cardiologists and verified by specialists in family heart disease.

After the clinical evaluation, the risk of sudden death at 5 years in patients with HCM was analysed using the risk calculator proposed by $\mathrm{O}^{\prime}$ Mahony et al. in 2014 [15]. The classifications are as follows: low risk for those who presented a value of $<4 \%$, moderate risk for those who presented a value between 4 and $6 \%$, and high risk for those who presented a value that exceeded $6 \%$.

\subsection{Statistical Analysis}

A descriptive analysis of all variables was carried out. With the categorical variables, the frequencies and global percentages were estimated. Normality tests and graphs were used to determine whether the quantitative variables followed a normal distribution. Variables with normal distribution were expressed as mean \pm standard deviation and those that did not have a normal distribution as a median and [interquartile range]. To describe the significance and associations between two variables, the chi-square test was used to face two qualitative categorical variables, and the Mann-Whitney U test was used to face a non-parametric quantitative variable to a qualitative one. A value of $p<0.05$ was considered to be an indicator of a significant difference. SPSS v.23 software was used for data analysis.

\section{Results}

\subsection{Description of the Analysed Population}

Eight families are described in the follow-up, with at least one patient diagnosed with HCM in the presence of the p.Arg652Lys variant (Table 1). A screening study was carried out in relatives of patients with HCM and with the p.Arg652Lys variant, which provided a total of 59 patients; of those, 39 (66\%) presented the variant in a heterozygous state.

Among the patients with the p.Arg652Lys variant, follow-up was performed for a median of 63 months (IQR (25-75): 23-112), observing the development of heart disease in $25(64 \%)$ carriers, with HCM being the only observed phenotype. No development of heart disease was detected in patients who did not carry the p.Arg652Lys variant. The median age of the patients at the time of the first clinical contact was 39 years (IQR [25-75]: 30.7-57.5), with those who carried the variant and had not developed HCM being younger (mean 
age 25.1 vs. 51.4; $p<0.0001$ ); that difference persisted in the last follow-up visit (mean age 29.6 vs. 58.2; $p<0.0001$ ). The ethnicity of all patients was Caucasian. Overall, $49 \%$ of carriers and $46 \%$ of those who developed HCM were female (Table 2).

Table 2. Demographic, electrocardiographic, and echocardiographic characterization of healthy carriers and HCM patients.

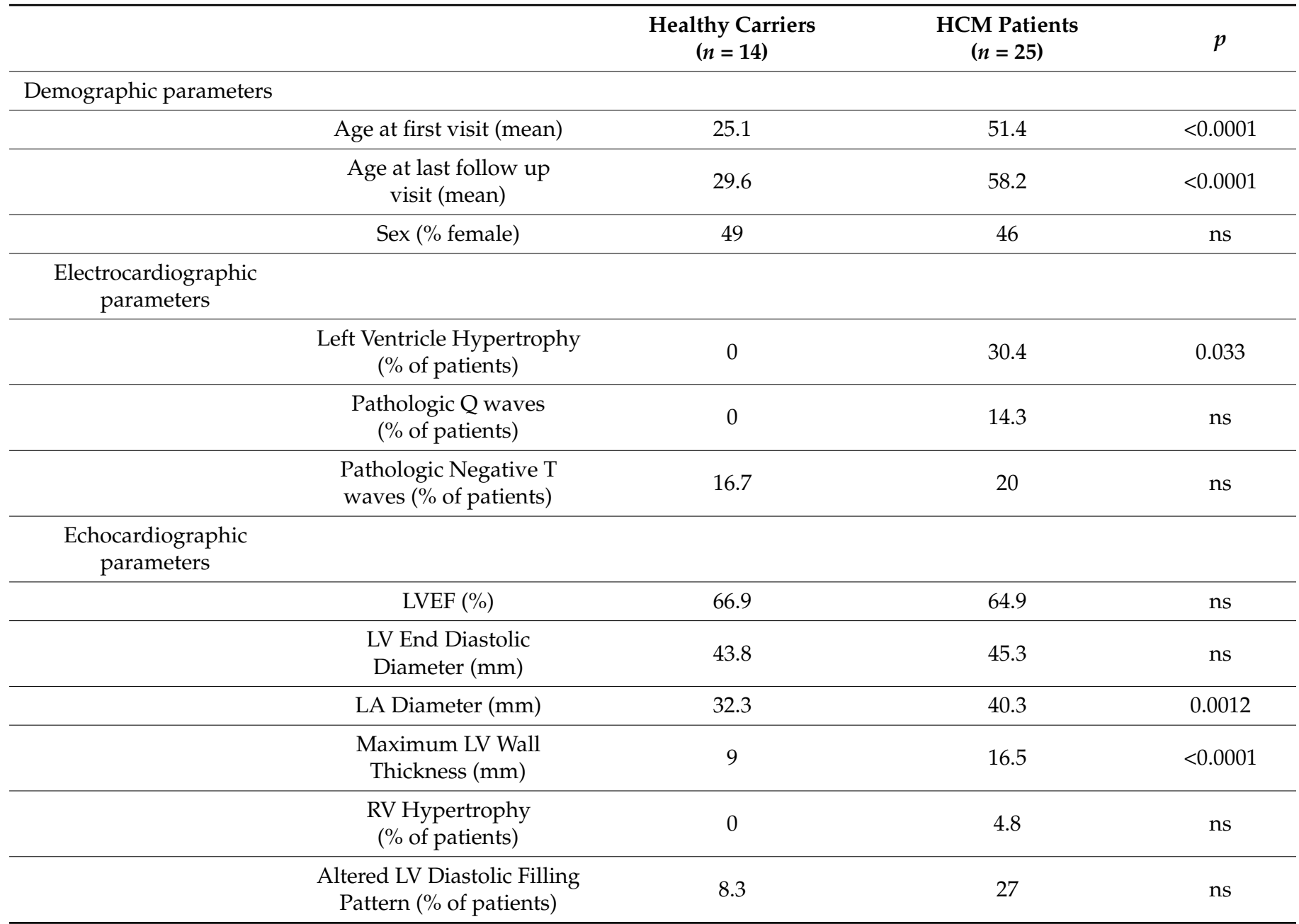

LA: Left Atrium, LV: Left Ventricle, LVEF: Left Ventricle Ejection Fraction, ns: not significant, RV: Right Ventricle.

In the group of patients who developed HCM, a median Maximum LVWT of 16.5 $\mathrm{mm}$ (IQR [25-75] 13.8-22 $\mathrm{mm}$ ) was described at follow-up. The morphology of ventricular hypertrophy was asymmetric septal in $75 \%$ of patients, concentric in $17 \%$ of patients, and apical in $8 \%$ of patients. A total of $28 \%$ of the patients presented obstruction to the $\mathrm{LV}$ outflow tract $(>30 \mathrm{mmHg}$ ) during follow-up, $8 \%$ presented episodes of non-sustained ventricular tachycardia (NSVT) using a 24-h Holter ECG, 4\% presented associated right ventricular hypertrophy, $12 \%$ had atrial fibrillation $(\mathrm{AF})$, and none reported impaired left ventricular function.

In $75 \%$ of the genetic studies of the index patients, the p.Arg652Lys variant was found in isolation, while a second variant associated with heart disease was found in two (25\%) of them.

In the first case, the p.Arg652Lys variant in MYH7 and the p.Arg190Trp variant in KCNQ1 were found. The latter is classified as likely pathogenic and associated with Long QT Syndrome, but no association with HCM has been found. In the second case (Figure 2), in addition to the p.Arg652Lys variant, an intronic variant of uncertain significance was found in the TPM1 gene (c.375-5T>C), which does not segregate the disease in the family. 


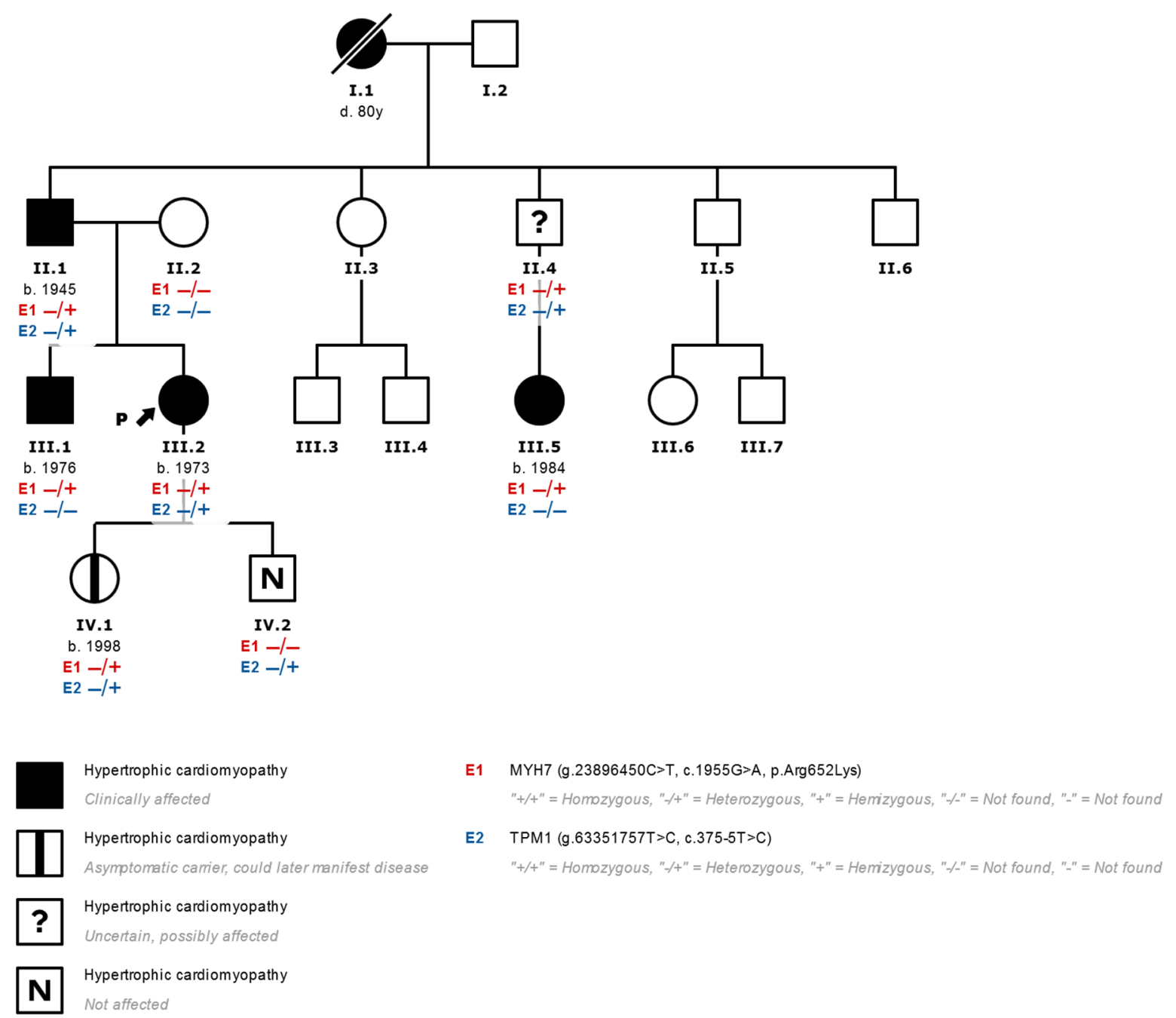

Figure 2. Family tree of a family studied with the finding of two variants that are potentially associated with heart disease (III.2 corresponds to index case $\mathrm{N}^{\circ} 5$ in Table 1 ). In genetic studies of patients with HCM and the finding of more than one variant that is not clearly associated with HCM, the pathogenicity of all the variants found should be considered and their family segregation evaluated. In this case, the presence of variants in the MYH7 (E1) and TPM1 (E2) genes is seen in the index case (arrow) with a diagnosis of HCM (effects indicated in black). We observed that only the variant p.Arg652Lys in MYH7 segregates together with the development of HCM in relatives, which is evident in the brother and in a cousin of the index case who presented HCM and only presented the variant in MYH7 without alterations in TPM1. Patients with the MYH7 variant and no HCM phenotype are marked with a central black mark. - /-: Variant not found. - /+: Heterozygous variant found.

\subsection{Analysis of Events during the Follow-Up}

In order to determine the risk of an unfavorable clinical course, the incidence of a composite of serious adverse cardiovascular events (ACEs) in patients with HCM, including sudden death (SD), aborted sudden death (ASD), appropriate implantable cardiac defibrillator (ICD) discharge, embolic events (stroke or peripheral ischemic event), and admission for heart failure (HF) in patients diagnosed with HCM was analysed.

The ACE compound was observed in five patients (20\%) (Table 3). The individual analysis of the variables revealed one (4\%) patient with SD, one (4\%) with ASD, and three $(12 \%)$ with embolic events, without registering any appropriate ICD discharge or admission for HF. Except for the ASD event that occurred at the age of 48, all other ACEs occurred at an age of 64 or higher (ACE median age 69.5; IQR [25-75]:60-75.5). 
Table 3. Incidence of clinical events in patients with findings of the p.Arg652Lys variant in MYH7.

\begin{tabular}{ccc}
\hline Clinical Events & & \\
\hline ACE (N-\%) & 5 & $20.0 \%$ \\
\hline Sudden Death (N-\%) & 1 & $4.0 \%$ \\
\hline SD under than 50 years of age (N-\%) & 0 & $0.0 \%$ \\
\hline Aborted SD (N-\%) & 1 & $4.0 \%$ \\
\hline Apropriate ICD discharge (N-\%) & 0 & $0.0 \%$ \\
\hline HF (N-\%) & 2 & $8.0 \%$ \\
\hline HF Admission (N-\%) & 0 & $0.0 \%$ \\
\hline AF (N-\%) & 3 & $12.0 \%$ \\
\hline Embolic Event (stroke or peripheral ischemic event) (N-\%) & 3 & $12.0 \%$ \\
\hline SRT (N-\%) & 1 & $4.0 \%$ \\
\hline Alcohol Ablation (N-\%) & 0 & $0.0 \%$ \\
\hline Myectomy (N- $\%)$ & 1 & $4.0 \%$ \\
\hline
\end{tabular}

ACE: Adverse Cardiovascular Event, AF: Atrial Fibrillation, ASD: Aborted Sudden Death, HF: Heart Failure, ICD: Implantable Cardiac Defibrillator, SD: Sudden Death, SRT: Septal Reduction Therapy.

The patients who presented ACEs had a higher incidence of AF ( $40 \%$ vs. $5 \%, p=0.031$ ).

The patients who presented SD and ASD at the time of the event had a low risk of sudden death (1.25\% and $2.11 \%$, respectively), according to the calculator by $\mathrm{O}^{\prime}$ Mahony et al., and a mean score that did not differ significantly from that calculated in the group that did not present SD or ASD (1.68 \pm 0.41 vs. $2.33 \pm 0.31, p=0.53)$.

It should be noted that we observed an additional SD event in a 70-year-old male patient, a carrier of the genetic variant p.Arg652Lys, who was genetically investigated after an ASD event in his sister. Since he did not have any cardiological follow-up, it is not possible to determine his clinical condition or to consider it to be sudden death associated with HCM in the event analysis.

Regarding invasive treatment, the need for septal reduction therapy has been described in one $(4 \%)$ patient due to the persistence of symptoms despite optimal medical treatment, with surgical myectomy being the treatment applied with good subsequent clinical evolution. In three (12\%) patients, the implantation of an ICD was indicated with the objective of primary prevention of sudden death, with the ICD being rejected by one of them and with the implantation being completed in the rest. No patients with LVEF deterioration $<50 \%$ at the time of diagnosis or during follow-up were found, and neither did patients with advanced heart failure require the transplantation or implantation of ventricular assist devices.

\section{Discussion}

Patients with HCM carry an increased risk of ACE throughout life. HCM has a prevalence of between $1 / 200$ and $1 / 500$ people [16] and is the leading cause of SD in patients under 35 years of age [17].

The genetic variant p.Arg652Lys is a missense change in the MYH7 gene that has not been described in population genetic studies. The GnomAd database (v2.1.1 data set that spans 125,748 exome sequences and 15,708 whole-genome sequences), ClinVar, and our private database at Unidad de Diagnóstico Molecular y Genética Clínica del Hospital Universitario Son Espases (including 1017 exomes from patients with very diverse diseases) were searched, and no description of the p.Arg652Lys variant was found. No publications consistent with its presence were associated with the development of HCM or any other form of heart disease. 
In 2002, MacCoss et al. [18] identified the p.Arg652 position of $\beta$-MHC as an important methylation site. However, the physiological significance of this modification is not conclusive.

There are missense-like variants that affect amino acids close to position 652 in $\beta$-MHC, which have been associated with the development of HCM.

The substitution of arginine for lysine is conservative in terms of the degree of structural variation of the molecule because both amino acids are similar, as they are basic residues. Despite this, position p.Arg652 is highly conserved in $\beta$-MHC, so a variant in this position could be detrimental.

A variant at this site that causes the amino acid substitution from arginine to glycine (p.Arg652Gly) has been associated with the development of the disease $[19,20]$ and is considered pathogenic in the development of HCM [21]. Although the variant described in our population shares the site of involvement, we cannot guarantee that it has the same functional effect.

A segregation analysis of the p.Arg652Lys variant was performed with the development of HCM in the aforementioned families, observing joint segregation of the variant and the HCM phenotype.

Following the ACMG/AMP classification (Table 4), we can see that the variant p.Arg652Lys meets the pathogenicity criteria based on the population information. This is because it is absent from population databases and segregation, after having described co-segregation in the eight families studied, and because it affects an active site of the protein $\beta$-MHC where a variant in the same amino acid has already been clearly established as pathogenic (p.Arg652Gly).

Table 4. Evidence framework for the pathogenicity classification of the p.Arg652Lys variant according to the criteria of the American College of Medical Genetics and Genomics (ACMG) and the Association for Molecular Pathology (AMP). In this diagram, the criteria are organised according to the type of evidence, as well as their strength.

\begin{tabular}{|c|c|c|}
\hline \multicolumn{3}{|c|}{ ACMG/AMP Clasification. } \\
\hline Class & Criteria for Interpretation & p.Arg652Lys Variant Interpretation [22] \\
\hline Pathogenic Moderate (PM1) & $\begin{array}{c}\text { Mutational hot spot and/or critical } \\
\text { and well-established functional } \\
\text { domain }\end{array}$ & $\begin{array}{l}\text { UniProt protein MYH7_HUMAN domain 'Myosin motor' has } \\
225 \text { pathogenic variants out of } 313 \text { classified variants }=71.9 \% \\
\text { (greater than } 66.7 \% \text { ). }\end{array}$ \\
\hline Pathogenic Moderate (PM2) & $\begin{array}{l}\text { Variant frequency and use of control } \\
\text { populations }\end{array}$ & $\begin{array}{c}\text { Variant not found in GnomAD exomes, with good GnomAD } \\
\text { exomes coverage ( } 87.1 \text { is greater than } 20.0 \text { ). Variant not found in } \\
\text { GnomAD genomes, with good GnomAD genomes coverage } \\
\text { (31.3 is greater than } 20.0) \text {. }\end{array}$ \\
\hline Pathogenic Moderate (PM5) & Novel missense at the same position & $\begin{array}{c}\text { Another amino acid missense variant at this position, } \\
\text { Arg652Gly (chr14:23896451 } \mathrm{T} \Rightarrow \mathrm{C} \text { ), is classified. Pathogenic, } \\
\text { two stars (above the minimum of one star) by ClinVar and } \\
\text { classified Likely Pathogenic using ACMG. }\end{array}$ \\
\hline Pathogenic Supporting (PP2) & Variant spectrum & $\begin{array}{c}\text { Missense variant in gene } M Y H 7 \text { that has } 412 \text { pathogenic } \\
\text { missense variants out of } 417 \text { pathogenic variants }=98.8 \% \text {, } \\
\text { which is greater than minimum of } 66.7 \% \text {, and only } 21 \text { benign } \\
\text { missense variants. Gene } M Y H 7 \text { is associated with } \\
\text { Cardiomyopathy, dilated, } 1 S \text {; Cardiomyopathy, familial } \\
\text { hypertrophic; Myopathy, distal; and Myopathy, myosin storage, } \\
\text { autosomal recessive. }\end{array}$ \\
\hline Pathogenic Supporting (PP3) & Computational (in silico) data & $\begin{array}{l}\text { Pathogenic computational verdict because of six pathogenic } \\
\text { predictions from DANN, GERP, dbNSFP.FATHMM, MetaLR, } \\
\text { MetaSVM, and MutationTaster (vs. three benign predictions } \\
\text { from MutationAssessor, PROVEAN, and SIFT). }\end{array}$ \\
\hline
\end{tabular}

Considering the p.Arg652Lys variant as likely pathogenic and associated with the development of HCM, it is possible to analyse its clinical behaviour. Penetrance is incomplete, reaching $64 \%$ in our population, and expressiveness is variable, with a very wide range of clinical expression ranging from the sole presence of left ventricular hypertrophy with no other associated manifestation to sudden death events at an age below 50 years. 
The risk assessment shows a behaviour of high clinical risk, with a high incidence of ACE that reaches $20 \%$ of the affected patients and $8 \%$ overall between SD and ASD events in patients with a confirmed HCM phenotype. Even though it is not possible to correctly describe an age-dependent analysis due to the small number of events, we can observe that adverse events occur at an advanced age, with only one ACE event at under 50 years of age.

Although we can observe that the HCM Risk-SCD score [15] does not differ significantly between the groups of patients who presented SD/ASD events and those who did not, it is not possible to define whether it is a useful risk stratification method in our study population since the small number of events makes statistical interpretation difficult.

\section{Limitations}

The present study is based on a small population of patients who have been followed for a limited period of time. Analysis in a larger numbers of patients is required over a long follow-up period to determine the true risk of adverse events in HCM patients due to the p.Arg652Lys variant.

\section{Conclusions}

Given the finding of the p.Arg652Lys variant in patients with HCM in our setting, but not described in controls, with evident segregation in patients with HCM from eight families and the location in an active site of the protein, which coincides with another variant previously described as pathogenic, we can define it as a likely pathogenic variant associated with the development of HCM, with incomplete penetrance and a high clinical risk in the series of patients described. The exclusive presence of the variant in our region could correspond to a founder effect in the Balearic Islands, Spain, which could be confirmed after further investigation.

Supplementary Materials: The following supporting information can be downloaded at: https: / / www.mdpi.com/article/10.3390/genes13020320/s1, Figure S1: Family tree; Figure S2: Family tree $\mathrm{N}^{\mathrm{o}}$ 2; Figure S3: Family tree $\mathrm{N}^{\mathrm{o}}$ 3; Figure S4: Family tree $\mathrm{N}^{\mathrm{o}}$ 4; Figure S5: Family tree $\mathrm{N}^{\mathrm{o}}$ 5.; Figure S6: Family tree $\mathrm{N}^{\mathrm{o}}$ 6; Figure S7: Family tree $\mathrm{N}^{\mathrm{o}}$ 7; Figure S8: Family tree $\mathrm{N}^{\mathrm{o}} 8$.

Author Contributions: Conceptualization, G.A., J.Á.-R. and T.R.-V.; methodology, T.R.-V.; formal analysis, G.A.; investigation, G.A., F.G.C.-M., J.Á.-R., P.M.-G., J.P.-L., B.R.-P., E.F.-F., L.T.-J., D.H.-S. and T.R.-V.; data curation, G.A.; writing-original draft preparation, G.A.; writing-review and editing, F.G.C.-M., J.Á.-R., P.M.-G., J.P.-L., B.R.-P., E.F.-F., L.T.-J., D.H.-S. and T.R.-V.; supervision, T.R.-V.; funding acquisition, T.R.-V. All authors have read and agreed to the published version of the manuscript.

Funding: The study was partly funded by the Instituto de Salud Carlos III through the CIBEROBN CB12/03/30038. D.H.S. has been funded by Instituto de Salud Carlos III through the project "PI18/00847" (cofunded by the European Regional Development Fund/European Social Fund's "A way to make Europe" /"Investing in your future").

Institutional Review Board Statement: The study was conducted according to the guidelines of the Declaration of Helsinki, and approved by the Institutional Ethics Committee of the Balearic Islands.

Informed Consent Statement: Informed consent was obtained from all subjects involved in the study.

Conflicts of Interest: The authors declare no conflict of interest.

\section{References}

1. Seidman, C.E.; Seidman, J.G. Identifying sarcomere gene mutations in hypertrophic cardiomyopathy: A personal history. Circ. Res. 2011, 108, 743-750. [CrossRef] [PubMed]

2. Ho, C.Y.; Day, S.M.; Ashley, E.A.; Michels, M.; Pereira, A.C.; Jacoby, D.; Cirino, A.L.; Fox, J.C.; Lakdawala, N.K.; Ware, J.S.; et al. Genotype and lifetime burden of disease in hypertrophic cardiomyopathy insights from the sarcomeric human cardiomyopathy registry (SHaRe). Circulation 2018, 138, 1387-1398. [CrossRef] [PubMed] 
3. Ommen, S.R.; Mital, S.; Burke, M.A.; Day, S.M.; Deswal, A.; Elliott, P.; Evanovich, L.L.; Hung, J.; Joglar, J.A.; Kantor, P.; et al. 2020 AHA/ACC Guideline for the Diagnosis and Treatment of Patients With Hypertrophic Cardiomyopathy. Circulation 2020, 142, 1387-1398. [CrossRef]

4. $\quad$ Paré, J.A.P.; Fraser, R.G.; Pirozynski, W.J.; Shanks, J.A.; Stubington, D. Hereditary cardiovascular dysplasia. A form of familial cardiomyopathy. Am. J. Med. 1961, 31, 37-62. [CrossRef]

5. Geisterfer-Lowrance, A.T.; Kass, S.; Tanigawa, G.; McKenna, W.; Seidman, C.E.; Seldmant, J.G. A Molecular Basis for Familial Hypertrophic Cardiomyopathy: A p Cardiac Myosin Heavy Chain Gene Missense Mutation. Cell 1990, 62, 999-1006. [CrossRef]

6. Sen-Chowdhry, S.; McKenna, W.J. Standing on the Shoulders of Giants: J.A.P. Paré and the Birth of Cardiovascular Genetics. Can. J. Cardiol. 2015, 31, 1305-1308. [CrossRef]

7. Ripoll-Vera, T.; Gámez, J.M.; Govea, N.; Gómez, Y.; Núñez, J.; Socías, L.; Escandell, Á.; Rosell, J. Clinical and Prognostic Profiles of Cardiomyopathies Caused by Mutations in the Troponin T Gene. Rev. Española Cardiol. 2016, 69, 1305-1308. [CrossRef]

8. Barriales-Villa, R.; Gimeno-Blanes, J.R.; Zorio-Grima, E.; Ripoll-Vera, T.; Evangelista-Masip, A.; Moya-Mitjans, A.; SerratosaFernández, L.; Albert-Brotons, D.C.; García-Pinilla, J.M.; García-Pavía, P. Plan of Action for Inherited Cardiovascular Diseases: Synthesis of Recommendations and Action Algorithms. Rev. Española Cardiol. 2016, 69, 149-158. [CrossRef]

9. Alejandra Restrepo-Cordoba, M.; Campuzano, O.; Ripoll-Vera, T.; Cobo-Marcos, M.; Mademont-Soler, I.; Gámez, J.M.; Dominguez, F.; Gonzalez-Lopez, E.; Padron-Barthe, L.; Lara-Pezzi, E.; et al. Usefulness of Genetic Testing in Hypertrophic Cardiomyopathy: An Analysis Using Real-World Data. J. Cardiovasc. Transl. Res. 2017, 10, 35-46. [CrossRef] [PubMed]

10. Walsh, R.; Mazzarotto, F.; Whiffin, N.; Buchan, R.; Midwinter, W.; Wilk, A.; Li, N.; Felkin, L.; Ingold, N.; Govind, R.; et al. Quantitative approaches to variant classification increase the yield and precision of genetic testing in Mendelian diseases: The case of hypertrophic cardiomyopathy. Genome Med. 2019, 11, 5. [CrossRef]

11. Ingles, J.; McGaughran, J.; Scuffham, P.A.; Atherton, J.; Semsarian, C. A cost-effectiveness model of genetic testing for the evaluation of families with hypertrophic cardiomyopathy. Heart 2012, 98, 625-630. [CrossRef] [PubMed]

12. Zamorano, J.L.; Anastasakis, A.; Borger, M.A.; Borggrefe, M.; Cecchi, F.; Charron, P.; Hagege, A.A.; Lafont, A.; Limongelli, G.; Mahrholdt, H.; et al. 2014 ESC guidelines on diagnosis and management of hypertrophic cardiomyopathy: The task force for the diagnosis and management of hypertrophic cardiomyopathy of the European Society of Cardiology (ESC). Eur. Heart J. 2014, 35, 2733-2779. [CrossRef]

13. SEC Working Group for the 2014 ESC Guidelines on Diagnosis and Management of Hypertrophic Cardiomyopathy; Expert Reviewers for the ESC 2014 Guidelines on the Diagnosis and Management of Hypertrophic Cardiomyopathy; SEC Clinical Practice Guidelines Committee. Comments on the 2014 ESC Guidelines on the diagnosis and management of hypertrophic cardiomyopathy. A critical view from the perspective of Spanish cardiology. Rev. Esp. Cardiol. 2015, 68, 4-9. [CrossRef]

14. Richards, S.; Aziz, N.; Bale, S.; Bick, D.; Das, S.; Gastier-Foster, J.; Grody, W.W.; Hegde, M.; Lyon, E.; Spector, E.; et al. Standards and guidelines for the interpretation of sequence variants: A joint consensus recommendation of the American College of Medical Genetics and Genomics and the Association for Molecular Pathology. Genet. Med. 2015, 17, 405-424. [CrossRef] [PubMed]

15. O'Mahony, C.; Jichi, F.; Pavlou, M.; Monserrat, L.; Anastasakis, A.; Rapezzi, C.; Biagini, E.; Gimeno, J.R.; Limongelli, G.; McKenna, W.J.; et al. A novel clinical risk prediction model for sudden cardiac death in hypertrophic cardiomyopathy (HCM Risk-SCD). Eur. Heart J. 2014, 35, 2010-2020. [CrossRef]

16. Semsarian, C.; Ingles, J.; Maron, M.S.; Maron, B.J. New Perspectives on the Prevalence of Hypertrophic Cardiomyopathy. J. Am. Coll. Cardiol. 2015, 65, 1249-1254. [CrossRef] [PubMed]

17. Maron, B.J.; Shirani, J.; Poliac, L.C.; Mathenge, R.; Roberts, W.C.; Mueller, F.O. Sudden death in young competitive athletes: Clinical, demographic, and pathological profiles. J. Am. Med Assoc. 1996, 276, 199-204. [CrossRef]

18. MacCoss, M.J.; McDonald, W.H.; Saraf, A.; Sadygov, R.; Clark, J.M.; Tasto, J.J.; Gould, K.L.; Wolters, D.; Washburn, M.; Weiss, A.; et al. Shotgun identification of protein modifications from protein complexes and lens tissue. Proc. Natl. Acad. Sci. USA 2002, 99, 7900-7905. [CrossRef] [PubMed]

19. Coto, E.; Reguero, J.R.; Palacn, M.; Gmez, J.; Alonso, B.; Iglesias, S.; Martn, M.; Tavira, B.; Daz-Molina, B.; Morales, C.; et al. Resequencing the whole MYH7 gene (including the intronic, promoter, and $3^{\prime}$ UTR sequences) in hypertrophic cardiomyopathy. J. Mol. Diagn. 2012, 14, 518-524. [CrossRef]

20. Ho, C.Y.; Sweitzer, N.K.; McDonough, B.; Maron, B.J.; Casey, S.A.; Seidman, J.G.; Seidman, C.E.; Solomon, S.D. Assessment of diastolic function with Doppler tissue imaging to predict genotype in preclinical hypertrophic cardiomyopathy. Circulation 2002, 105, 2992-2997. [CrossRef]

21. Coppini, R.; Ho, C.Y.; Ashley, E.; Day, S.; Ferrantini, C.; Girolami, F.; Tomberli, B.; Bardi, S.; Torricelli, F.; Cecchi, F.; et al. Clinical phenotype and outcome of hypertrophic cardiomyopathy associated with thin-filament gene mutations. J. Am. Coll. Cardiol. 2014, 64, 2589-2600. [CrossRef] [PubMed]

22. Kopanos, C.; Tsiolkas, V.; Kouris, A.; Chapple, C.E.; Aguilera, M.A.; Meyer, R.; Massouras, A. VarSome: The human genomic variant search engine I Bioinformatics I Oxford Academic. Bioinformatics 2019, 35, 1978-1980. [CrossRef] [PubMed] 